\title{
Unravelling the Role of Temperature and Photoperiod on Poinsettia Heat Delay
}

\author{
Michael Alden and James E. Faust \\ Department of Plant and Environmental Sciences, Clemson University, \\ Clemson, SC 29634
}

Additional index words. floriculture, flowering, flower initiation, greenhouse production, night length

\begin{abstract}
The effects of day temperature (DT), night temperature (NT), and night length (NL) were evaluated on the flowering responses of heat-tolerant and heat-sensitive poinsettia (Euphorbia pulcherrima Willd. ex Klotzsch) cultivars Orion Red and Prestige Red, respectively. Plants were placed under $60 \mathrm{DT} \times \mathrm{NT} \times \mathrm{NL}$ treatments that consisted of three DT $\left(20,24,28^{\circ} \mathrm{C}\right)$, four NT $\left(16,20,24,28^{\circ} \mathrm{C}\right)$, and five $\mathrm{NL}(10,11,12,13,14$ hours) for the first 17 days of the experiment. After 17 days, all plants were consolidated to one greenhouse with an inductive environment (14-hour NL, $24 \pm 2.0^{\circ} \mathrm{C}$ DT and $21.2 \pm 1.4^{\circ} \mathrm{C} \mathrm{NT}$ ), and the timing of first color, visible bud, and anthesis were recorded. 'Orion Red' reached anthesis 8 to 10 days faster than 'Prestige Red' across all NLs; however, in both cultivars, days to anthesis decreased in a sigmoidal pattern as NL increased. The relative rate of progress to anthesis (1/days to anthesis) under a 12-hour NL was approximately half that of plants grown at a 13- or 14-hour NL. At a 12-hour NL, the relative rate of progress to anthesis decreased linearly as DT increased for both cultivars. At 13- to 14-hour NL, DT had relatively little effect on the relative rate of progress to anthesis. Thus, high DT delayed flowering of both heat-tolerant and heat-sensitive cultivars when flower initiation occurred under NL, typical of naturally occurring NLs in September and early October (i.e., 12-hour NL), whereas high DT did not delay flowering for either cultivar under a 14-hour $\mathrm{NL}$, which is typically provided under black cloth systems. In contrast, the flowering responses to NT were quite different for the two cultivars. The heat-tolerant cultivar showed relatively little change in the relative rate of progress to anthesis as NT increased from 16 to $28^{\circ} \mathrm{C}$ within each NL treatment; however, the heat-sensitive cultivar displayed a large decrease in the relative rate progress to anthesis as NT increased from 20 to $28{ }^{\circ} \mathrm{C}$ within each NL treatment. Although the delayed flowering that occurred at $28{ }^{\circ} \mathrm{C}$ and 14-hour NL was significant, the relative rate of progress to anthesis at this treatment was significantly higher than the $28{ }^{\circ} \mathrm{C}$ and 12-hour NL treatment. This suggests that artificially shortening NL to 14 hours with a black cloth system does not prevent heat delay of poinsettia, but it allows for more rapid flowering than if flower initiation took place under natural NL $(\approx 12$ hours $)$. To summarize, high DT affected flowering when flower initiation took place at 12-hour NL for heat-tolerant and heat-sensitive poinsettia cultivars, whereas high NT uniquely delayed flowering of the heat-sensitive cultivar at NL from 12 to 14 hours.
\end{abstract}

Poinsettia is a short-day plant that begins to initiate flowers around the time of the autumnal equinox (21 Sept.) when NLs become sufficiently long and thereby inductive (Ecke et al., 2004). Flower initiation can be delayed by exposure to supra-optimal

Received for publication 26 Mar. 2021. Accepted for publication 24 June 2021.

Published online 9 August 2021.

Technical Contribution No. 6996 of the Clemson University Experiment Station. This material is based on work supported by National Institute of Food and Agriculture/U.S. Department of Agriculture (USDA), under project number SC1700585. We recognize the USDA-ARS Floriculture and Nursery Research Initiative for the financial support of this project.

J.E.F. is the corresponding author. E-mail: jfaust@ clemson.edu.

This is an open access article distributed under the CC BY-NC-ND license (https://creativecommons. org/licenses/by-nc-nd/4.0/).
Hackett, 1965; Langhans and Larson, 1959; Langhans and Miller, 1959; Roberts and Struckmeyer, 1938). Berghage et al. (1987) provided evidence that supra-optimal NT was the cause of heat delay. This study used a full factorial experiment consisting of 36 DT and NT treatments from six temperatures $(14,17$, $20,23,26$, and $29^{\circ} \mathrm{C}$ ) provided to 'Annette Hegg Dark Red' grown under 14-h NLs for the duration of the experiment. Results from this experiment clearly demonstrated that NT $\geq 26^{\circ} \mathrm{C}$ delayed bract coloration and inhibited cyathia development regardless of DT. The researchers suggested that growers need to maintain NT of $\leq 23^{\circ} \mathrm{C}$ to avoid heat delay.

Schnelle (2008) conducted a poinsettia heat delay study that seemingly contradicted those obtained by Berghage et al. (1987). Four poinsettia cultivars were grown under four DT/NT combinations $\left(23 / 19,26 / 22,24 / 24\right.$, and $\left.29 / 24^{\circ} \mathrm{C}\right)$ that provided three ADT treatments $(21,24$, and $27^{\circ} \mathrm{C}$ ), while the plants were grown under 12-h NLs for the duration of the experiment. The $27^{\circ} \mathrm{C}$ ADT $\left(29 / 24^{\circ} \mathrm{C}\right)$ treatment was significantly delayed in time to first bract color, visible bud, and anthesis compared with the other three DT/NT treatments. As a result, the researcher suggested that growers need to maintain $\leq 24{ }^{\circ} \mathrm{C}$ ADT, although one could also have concluded that $\leq 26^{\circ} \mathrm{C}$ DT would also avoid heat delay.

The apparent discrepancy among the research literature concerning whether supraoptimal NT, DT, or ADT causes heat delay has left poinsettia growers uncertain as to how to manage the greenhouse environment during flower initiation and development of poinsettias. The general consensus in the industry has been that the experimental differences were due to the different cultivars grown and that modern cultivars respond to temperature differently from older cultivars. Our hypothesis is that the photoperiodic flowering response of poinsettia is modified by temperature. Thus, the differing heat delay responses reported by Schnelle (2008) and Berghage et al. (1987) are due the different photoperiods provided in their studies (e.g., a 12-h vs. a 14-h NL).

The objective of this project was to examine the interaction of DT, NT, and NL on poinsettia flowering with the goal of improving our understanding of the environmental conditions that lead to poinsettia heat delay. We focused on the early stages of flowering (flower initiation) for two reasons. First, flower initiation is when poinsettias appear to be most sensitive to heat delay (Schnelle et al., 2006). Second, results from experiments that provide temperature treatments throughout the entire flowering period can be difficult to interpret; for example, high temperatures may delay flower initiation, but once initiation occurs, the same high temperatures may be optimal for flower development (Camberato et al., 2012).

\section{Materials and Methods}

Two poinsettia cultivars, Orion Red and Prestige Red, were selected for this experiment 
to evaluate heat-tolerant and heat-sensitive flowering responses, respectively. Three hundred cuttings of each cultivar were propagated in a foam medium (Oasis Rootcubes Plus Wedge, Smithers-Oasis, Kent, $\mathrm{OH}$ ) in a greenhouse under long-day conditions that consisted of LED bulbs (9W LED A19 Light Bulb; Utilitech, West Lawn, PA) that delivered $1.2 \pm 0.2$ $\mu \mathrm{mol} \cdot \mathrm{m}^{-2} \cdot \mathrm{s}^{-1}$ from 1630 to $0000 \mathrm{HR}$ daily. After $21 \mathrm{~d}$, cuttings were transplanted into 1.33-L containers with a peat-based growing medium (Fafard 3B; Sun Gro, Anderson, SC) and provided long-day (8-h NL) conditions in a greenhouse equipped with metal halide lamps that delivered $175 \pm 25 \mu \mathrm{mol} \cdot \mathrm{m}^{-2} \cdot \mathrm{s}^{-1}$ from 0800 to 0000 HR daily. Plants were grown with a constant liquid fertilization program consisting of a $150 \mathrm{mg} \cdot \mathrm{L}^{-1} \mathrm{~N}$ solution made with $15 \mathrm{~N}-2.2 \mathrm{P}-12.5 \mathrm{~K}$ (Peters' Excel Cal-Mag Special; J.R. Peters, Allentown, PA). Ten days after transplant, plants were pinched to five nodes and vegetative growth continued for 4 weeks. The most uniform 240 plants from each cultivar were selected, thinned to three axillary shoots, and randomly assigned to each of 60 temperature $\times$ photoperiod treatments for $17 \mathrm{~d}$. The treatments consisted of a factorial arrangement made up of three DTs $\left(20,24\right.$, or $\left.28^{\circ} \mathrm{C}\right)$, four NTs $\left(16,20,24\right.$, or $\left.28^{\circ} \mathrm{C}\right)$, and five NLs $(10,11,12,13$, or $14 \mathrm{~h})$, and each of the 60 $\mathrm{DT} \times \mathrm{NT} \times \mathrm{NL}$ treatments were assigned four plants per cultivar.

To achieve the temperature $\times$ photoperiod treatments, four greenhouses (lat. $34.7^{\circ} \mathrm{N}$ ) provided one of four temperatures $(16,20$, 24 , or $28^{\circ} \mathrm{C}$ ) throughout the experiment, and the $12 \mathrm{DT} / \mathrm{NT}$ combinations were achieved by moving plants among greenhouses at the beginning and the end of each photoperiod. A $16^{\circ} \mathrm{C}$, DT treatment was not provided because it was not possible to accurately maintain this temperature. Weather stations (Argus Controls, Surrey, B.C., Canada) continuously measured the temperatures within each greenhouse. For the purpose of calculating the greenhouse temperatures, the day was defined as the period from 0800 to $2000 \mathrm{HR}$, and the actual temperatures for the 20,24, and $28^{\circ} \mathrm{C}$ greenhouses were $19.7 \pm 1.2$, $23.8 \pm 0.7$, and $27.9 \pm 1.9^{\circ} \mathrm{C}$, respectively. Night was defined as 2000 to $0800 \mathrm{HR}$, and the actual temperatures for the $16,20,24$, and $28^{\circ} \mathrm{C}$ greenhouses were $16.2 \pm 0.9$, $19.9 \pm 0.6,23.9 \pm 0.2$, and $27.3 \pm 1.0^{\circ} \mathrm{C}$, respectively.

Within each greenhouse, two benches $(7.3 \mathrm{~m} \times 1.5 \mathrm{~m})$ were subdivided into three sections $(2.43 \mathrm{~m} \times 1.5 \mathrm{~m} \times 0.9 \mathrm{~m})$ and separated with aluminized radiant barriers (Double Reflective Insulation; Reflectix Inc., Markleville, IN) to prevent light pollution from neighboring treatments. Five bench sections within a greenhouse were randomly assigned an NL treatment $(10,11,12,13$, or $14 \mathrm{~h}$ ) with one of the six sections not being used. Within each of the five bench sections, four white LED bulbs were hung above the plants to provide day-length-extension lighting. The white LED bulbs were controlled with timers that turned on daily at $1730 \mathrm{HR}$, and black cloth was pulled over the benches at the same time. Each evening the white LED bulbs turned off at 1800, 1900, 2000, 2100 , or $2200 \mathrm{HR}$ in each of the five photoperiod sections to provide the 14-, 13-, 12-, 11or 10-h NL treatments, respectively. The black cloth was pulled off the benches at 0800 HR daily. Sunrise occurred before 0800 HR throughout the experimental period, so the photoperiod treatments started promptly at $0800 \mathrm{HR}$ daily when the black cloth was removed.

The plants were transported on carts between greenhouses in lit corridors $\approx 20 \mathrm{~min}$ before the termination of daylight extension periods so that the photoperiod treatments were uninterrupted and the NLs were precise. At $0800 \mathrm{HR}$, black cloth was removed from all greenhouse benches and plants were moved to their assigned DT treatment. Movment took 20 to $30 \mathrm{~min}$. Thus, the plants were exposed to the setpoint DT or NT for their respective temperature treatment for the entire duration of their photoperiod/NL treatment. After $17 \mathrm{~d}$, all plants were consolidated to one greenhouse with an inductive environment (14-h NL, $24 \pm 2.0^{\circ} \mathrm{C}$ DT, and $21.2 \pm$ $1.4^{\circ} \mathrm{C} \mathrm{NT}$ ) and grown to anthesis.

Data were collected when plants reached first color, visible bud, and anthesis. First color was determined on each stem when a green leaf had a distinctive blush of red pigmentation. Visible bud was identified when the primary cyathium was clearly visible $(\approx 2$ $\mathrm{mm}$ in diameter). Anthesis was identified on the first stamen to bear pollen from the primary cyathium. Progress to anthesis was calculated as the reciprocal of days to anthesis, and data were scaled between 0 and 1 . A tag was hung on the most recently mature expanded leaf on each stem at the beginning of temperature $\times$ photoperiod treatments, and the number of nodes on each stem above the tag was counted at anthesis. The experiment was performed twice with replications beginning on 14 Sept. 2018 and 1 Feb. 2019; these dates are the first day that the poinsettias ing plants back to the appropriate DT treat-

were placed under the temperature $\times$ photoperiod treatments. Both replications followed the same procedures except that plants were grown nonpinched (i.e., with a single stem per plant during the second replication).

Statistical analysis of data was performed using JMP Pro (v. 14.0; SAS Institute Inc., Cary, NC). Analysis of variance (ANOVA) tests were conducted to evaluate the significance of each factor and their interactions on each of the three flowering responses. Each flowering response was transformed by taking the reciprocal of the number of days to reach a given response to estimate the amount of progress made during the $17 \mathrm{~d}$ when treatments were applied. Least squares means were calculated for each of the 60 photoperiod $\times$ temperature treatments, and then these treatment means were scaled between 0 and 1. For example, the rate of progress to anthesis was calculated as the reciprocal of days to anthesis, and the calculated least squares means for each photoperiod $\times$ temperature treatment were scaled between 0 and 1 . The treatment with the fastest progress to anthesis rate (fewest days to anthesis) was set equal to 1 and the treatment with the slowest progress to anthesis rate (greatest days to anthesis) was set equal to 0. Data for 'Orion Red' and 'Prestige Red' were transformed independent of each other.

\section{Results and Discussion}

The ANOVA of the full experimental factorial demonstrated large differences in time to anthesis across cultivars and NLs (Table 1; Fig. 1). Although the four-way interaction (cultivar $\times \mathrm{NL} \times \mathrm{DT} \times \mathrm{NT}$ ) is statistically significant, the main effects of NL and cultivar have extremely large F-ratios for time to anthesis (750 and 1675, respectively), so Fig. 1 displays these main effects. 'Orion Red' reached anthesis 8 to $10 \mathrm{~d}$ faster than 'Prestige Red' across all NLs; however, in both cultivars, days to anthesis decreased in a sigmoidal pattern as NL increased. Both

Table 1. Analysis of variance table demonstrating the significance of each main effect, including cultivar (Cvr), night length (NL), day temperature (DT), and night temperature (NT), and their interactions across all three floral responses: days from start of the experiment to first color, visible bud, and anthesis.

\begin{tabular}{|c|c|c|c|c|c|c|}
\hline \multirow[b]{2}{*}{ Factor } & \multicolumn{2}{|c|}{ First color } & \multicolumn{2}{|c|}{ Visible bud } & \multicolumn{2}{|c|}{ Anthesis } \\
\hline & $\mathrm{F}$ ratio & Significance & $\mathrm{F}$ ratio & Significance & $\mathrm{F}$ ratio & Significance \\
\hline$\overline{\mathrm{Cvr}}$ & 4762.5 & $* * *$ & 657.9 & $* * *$ & 1675.2 & $* * *$ \\
\hline NL & 1252.0 & $* * *$ & 873.3 & $* * *$ & 750.8 & $* * *$ \\
\hline DT & 18.6 & $* * *$ & 57.4 & $* * *$ & 10.8 & $* * *$ \\
\hline NT & 54.6 & $* * *$ & 59.1 & $* * *$ & 43.5 & $* * *$ \\
\hline $\mathrm{Cvr} \times \mathrm{NL}$ & 11.8 & $* * *$ & 6.9 & $* * *$ & 2.8 & $*$ \\
\hline $\mathrm{Cvr} \times \mathrm{DT}$ & 6.7 & $* *$ & 0.3 & NS & 0.1 & NS \\
\hline $\mathrm{Cvr} \times \mathrm{NT}$ & 46.7 & $* * *$ & 30.1 & $* * *$ & 19.6 & $* * *$ \\
\hline $\mathrm{NL} \times \mathrm{DT}$ & 17.2 & $* * *$ & 17.6 & $* * *$ & 15.4 & $* * *$ \\
\hline $\mathrm{NL} \times \mathrm{NT}$ & 8.0 & $* * *$ & 4.1 & $* * *$ & 4.8 & $* * *$ \\
\hline $\mathrm{DT} \times \mathrm{NT}$ & 0.9 & NS & 1.0 & NS & 0.5 & NS \\
\hline $\mathrm{Cvr} \times \mathrm{NL} \times \mathrm{DT}$ & 0.7 & NS & 2.1 & $*$ & 2.9 & $* *$ \\
\hline $\mathrm{Cvr} \times \mathrm{NL} \times \mathrm{NT}$ & 6.2 & $* * *$ & 3.1 & $* *$ & 3.4 & $* * *$ \\
\hline $\mathrm{Cvr} \times \mathrm{DT} \times \mathrm{NT}$ & 1.2 & NS & 1.6 & NS & 1.4 & NS \\
\hline $\mathrm{NL} \times \mathrm{DT} \times \mathrm{NT}$ & 1.2 & NS & 2.3 & $* *$ & 1.5 & NS \\
\hline $\mathrm{Cvr} \times \mathrm{NL} \times \mathrm{DT} \times \mathrm{NT}$ & 0.9 & NS & 1.8 & $* *$ & 1.8 & $*$ \\
\hline
\end{tabular}

$\mathrm{NS}, *, * *, * * *$ Nonsignificant or significant at $P<0.05,0.01$, or 0.001 , respectively. 


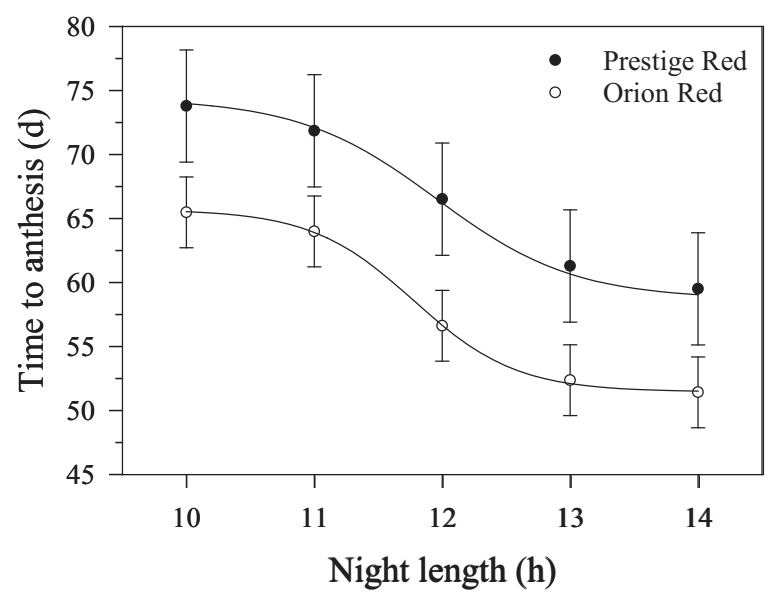

Fig. 1. Poinsettia 'Orion Red' and 'Prestige Red' were placed under night lengths (NL) of 10, 11, 12, 13 , and $14 \mathrm{~h}$ for $17 \mathrm{~d}$ and then consolidated to a fully inductive environment (14-h NL, 24/20 ${ }^{\circ} \mathrm{C}$ day/night temperature). Data points in each night length treatment represent the mean value associated with the $12 \mathrm{~d} /$ night temperature combinations applied during the $17 \mathrm{~d}$ of treatments. Error bars represent $\pm 1 \mathrm{SE}$. cultivars showed a slight decrease in days to anthesis when NL increased from 10 to $11 \mathrm{~h}$ and from 13 to $14 \mathrm{~h}$, whereas a large decrease occurred between 11 and $13 \mathrm{~h}$. 'Orion Red' had the largest decrease in days to anthesis $(8$ d) when NL increased from 11 to $12 \mathrm{~h}$, whereas time to anthesis decreased in 'Prestige Red' by $5 \mathrm{~d}$ when NL increased from 11 to $12 \mathrm{~h}$ and from 12 to $13 \mathrm{~h}$. The center of poinsettia biodiversity occurs in the state of Guerrero, Mexico (lat. $\approx 18.6^{\circ} \mathrm{N}$ ) (Trejo et al., 2012). At this latitude, NL measured by the U.S. Naval Observatory (2007) from civil twilight to civil twilight ranges from $10 \mathrm{~h} 59 \mathrm{~min}$ to $13 \mathrm{~h} 01 \mathrm{~min}$. The interaction of NL $\times$ cultivar is also significant $(\mathrm{F}$ ratio $=2.8)$ and can be seen by the shift in the inflection point from $11.8 \mathrm{~h}$ for 'Orion Red' to $12.0 \mathrm{~h}$ for 'Prestige Red'. At lat. $34.7^{\circ} \mathrm{N}, \mathrm{NL}$ increases at a rate of $\approx 2$ min per night in September and October, thus this shift in the inflection point represents a 12-min shift in the NL required to reach $50 \%$ of the optimal flowering response time,

which represents a 6-d difference between cultivars at this latitude and season.

The difference in the number of days from first color to anthesis and from visible bud to anthesis were evaluated to determine if the timing of anthesis could be predicted once first color or visible bud occurs (Table 2 ). The time from first color to anthesis was affected only by cultivar; 'Orion Red' reached anthesis $32.0 \pm 0.23 \mathrm{~d}$ after first color, whereas 'Prestige Red' reached anthesis $30.3 \pm 0.33 \mathrm{~d}$ after first color across all treatments. Thus, when first color is observed and moderate temperatures are expected through the remainder of the crop time, commercial growers can expect that anthesis will occur $\approx 30$ to $32 \mathrm{~d}$ later. Similarly, the time from visible bud to anthesis was also affected by cultivar; Orion Red reached anthesis $21.4 \pm 0.35 \mathrm{~d}$ after visible bud, whereas Prestige Red reached anthesis $25.4 \pm 0.36 \mathrm{~d}$ later. The interaction of cultivar $\times \mathrm{NT} \times \mathrm{NL}$ was statistically significant with regard to the time from visible bud to anthesis. For 'Orion Red', no clear trends occurred and the

Table 2. Analysis of variance table demonstrating the significance of each main effect, including cultivar (Cvr), night length (NL), day temperature (DT), and night temperature (NT), and their interactions on the number of days from first color to anthesis and from visible bud to anthesis.

\begin{tabular}{|c|c|c|c|c|}
\hline \multirow[b]{2}{*}{ Factor } & \multicolumn{2}{|c|}{ Days from first color to anthesis } & \multicolumn{2}{|c|}{ Days from visible bud to anthesis } \\
\hline & $\mathrm{F}$ ratio & Significance & $\mathrm{F}$ ratio & Significance \\
\hline$\overline{\mathrm{Cvr}}$ & 12.6 & $* *$ & 63.9 & $* * *$ \\
\hline DT & 0.4 & NS & 0.5 & NS \\
\hline NT & 0.0 & NS & 0.2 & NS \\
\hline NL & 0.7 & NS & 4.9 & $*$ \\
\hline $\mathrm{Cvr} \times \mathrm{DT}$ & 0.0 & NS & 0.0 & NS \\
\hline Cvr $\times$ NT & 0.0 & NS & 0.5 & NS \\
\hline $\mathrm{Cvr} \times \mathrm{NL}$ & 0.1 & NS & 0.0 & NS \\
\hline $\mathrm{DT} \times \mathrm{NT}$ & 0.3 & NS & 3.0 & NS \\
\hline $\mathrm{DT} \times \mathrm{NL}$ & 2.8 & NS & 0.9 & NS \\
\hline $\mathrm{NT} \times \mathrm{NL}$ & 0.0 & NS & 1.1 & NS \\
\hline $\mathrm{Cvr} \times \mathrm{DT} \times \mathrm{NT}$ & 0.0 & NS & 0.2 & NS \\
\hline $\mathrm{Cvr} \times \mathrm{DT} \times \mathrm{NL}$ & 0.4 & NS & 0.5 & NS \\
\hline $\mathrm{Cvr} \times \mathrm{NT} \times \mathrm{NL}$ & 0.4 & NS & 6.9 & $* *$ \\
\hline $\mathrm{DT} \times \mathrm{NT} \times \mathrm{NL}$ & 1.1 & NS & 0.1 & NS \\
\hline $\mathrm{Cvr} \times \mathrm{DT} \times \mathrm{NT} \times \mathrm{NL}$ & 0.0 & NS & 0.0 & NS \\
\hline
\end{tabular}

$\mathrm{NS}, *, * *, * * *$ Nonsignificant or significant at $P<0.05,0.01$, and 0.0001 , respectively. difference in time from visible bud to anthesis was $\leq 2 \mathrm{~d}$ across all treatments (i.e., all treatments reached anthesis between 20 to 22 $\mathrm{d}$ after visible bud). For 'Prestige Red', time from visible bud to anthesis was 24 to $26 \mathrm{~d}$ except for the $16^{\circ} \mathrm{C}$ NT treatments where the time from visible bud to anthesis decreased from 27 to $21 \mathrm{~d}$ as NL increased from 11 to $14 \mathrm{~h}$.

Each data point in the DT figures for the two cultivars (Figs. 2A, C, E and 3A, C, and E) represents the relative rate of progress made to first color, visible bud, or anthesis during the $17 \mathrm{~d}$ across the four NTs and vice versa for the NT figures (Figs. 2B, D, and F and $3 \mathrm{~B}, \mathrm{D}$, and $\mathrm{F}$ ). Thus, all 60 temperature $\times$ photoperiod treatments are represented in each DT and NT figure. The actual days to each of the three flower development measurements can be calculated with the following equation: $17-$ (relative progress to flower $\times$ 17) + minimum days to each event, where the minimum days to first color, visible bud, and anthesis were 18, 28, and 48 for 'Orion Red', and 26, 32, and 55, for 'Prestige Red', respectively.

At the 10-h NL, the heat-tolerant cultivar, Orion Red, made significantly more progress to visible bud and anthesis at a DT of $20^{\circ} \mathrm{C}$ compared with 24 and $28^{\circ} \mathrm{C}$ (Fig. $2 \mathrm{C}$ and E) during the first $17 \mathrm{~d}$ of treatments, whereas no DT response was noted for first color (Fig. 2A). At the 11-h NL, progress to all three flowering responses increased if DT was $20^{\circ} \mathrm{C}$ compared with 24 and $28^{\circ} \mathrm{C}$. At the 12-h NL, 'Orion Red' showed a linear decrease in progress to all three flowering responses as DT increased from 20 to $28^{\circ} \mathrm{C}$. At the 13-h NL, little change occurred in progress made to the three flowering responses compared with the $12-\mathrm{h} \mathrm{NL}$ if DT was $20^{\circ} \mathrm{C}$; however, at 24 and $28{ }^{\circ} \mathrm{C}$, increasing NL from 12 to 13 or $14 \mathrm{~h}$ resulted in a significant increase in progress made to all three flowering responses.

The flowering responses of 'Orion Red' to NT demonstrated relatively small responses from 16 to $28^{\circ} \mathrm{C}$; however, NT from 20 to $24^{\circ} \mathrm{C}$ tended to be optimal at NL from 11 to $14 \mathrm{~h}$ (Fig. 2B, D, and F). In general, the relative rate of progress to first color, visible bud, and anthesis showed a significant increase as NL increased from 11 to $13 \mathrm{~h}$, whereas little to no difference was observed between NLs of 13 and $14 \mathrm{~h}$ at NT of 20 and $24{ }^{\circ} \mathrm{C}$.

For the heat-sensitive cultivar, Prestige Red, no differences in progress to first color, visible bud, and anthesis were observed for the different DT treatments at the 10-h NL (Fig. 3A, C, and E). At the 11-h NL, progress to each of the three flowering responses increased at $20^{\circ} \mathrm{C}$ DT compared with the 10 $\mathrm{h}$ NL treatments. At the 12-h NL, 'Prestige Red' showed a linear decrease in progress to each of the three flowering responses as DT increased. No differences in progress to the three flowering responses across the DT treatments were observed at $13-\mathrm{h} \mathrm{NL}$, whereas 14-h NLs resulted in a greater relative rate of progress to anthesis at 24 and $28^{\circ} \mathrm{C}$ DT. 

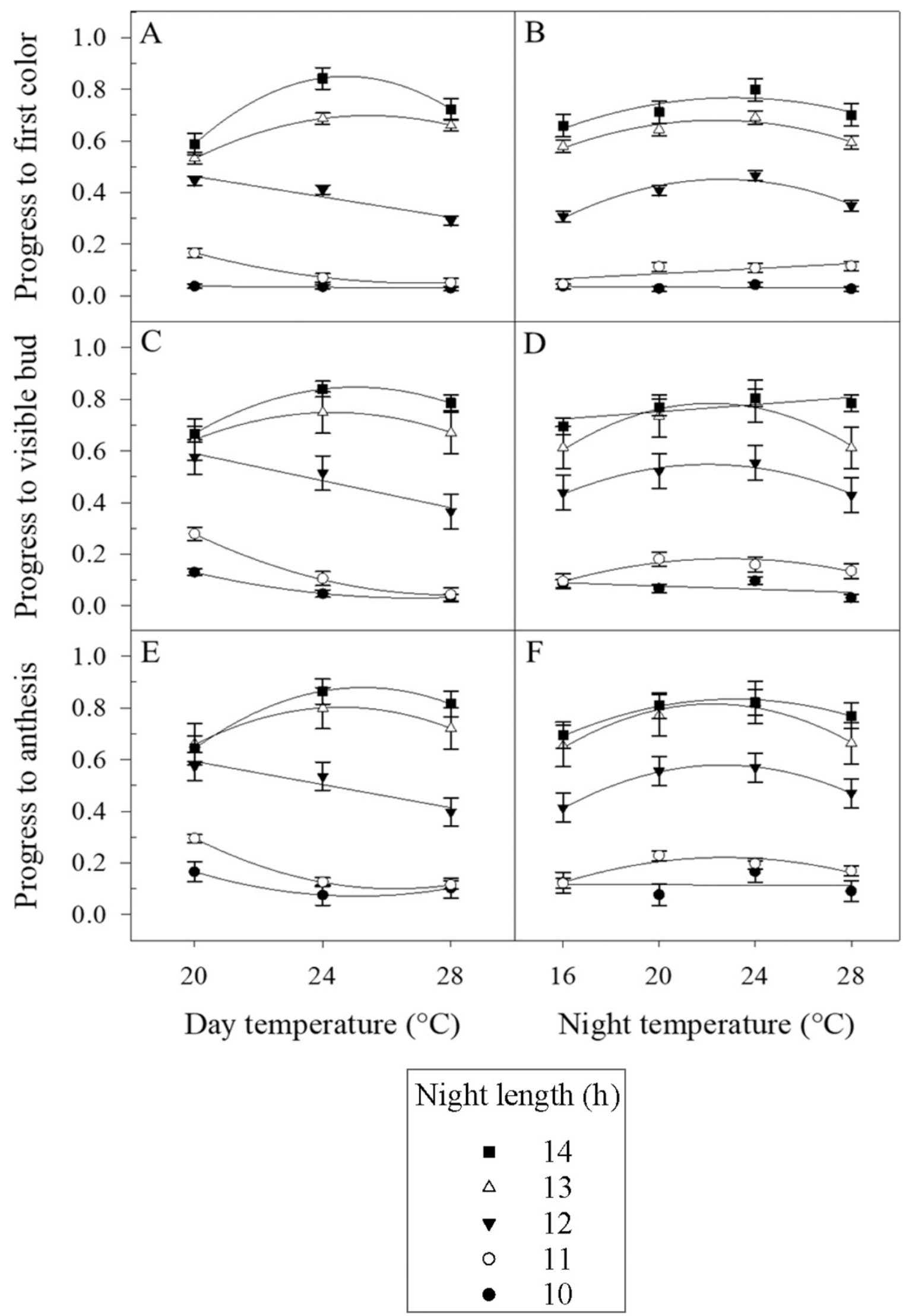

Fig. 2. Poinsettia 'Orion Red' plants were placed under night lengths (NL) of 10,11, 12, 13, or $14 \mathrm{~h}$ for $17 \mathrm{~d}$ and then consolidated to a fully inductive environment (14-h NL, $24 / 20^{\circ} \mathrm{C}$ day/night temperature) until anthesis. The relative rate of progress to first color, visible bud, and anthesis are reported for each day temperature $(\mathbf{A}, \mathbf{C}, \mathbf{E})$ and night temperature $(\mathbf{B}, \mathbf{D}, \mathbf{F})$ treatment. Each data point in the day temperature figures represents the average time to reach a flowering response across the four night temperatures and vice versa for the night temperature figures. Error bars represent \pm 1 SE. 

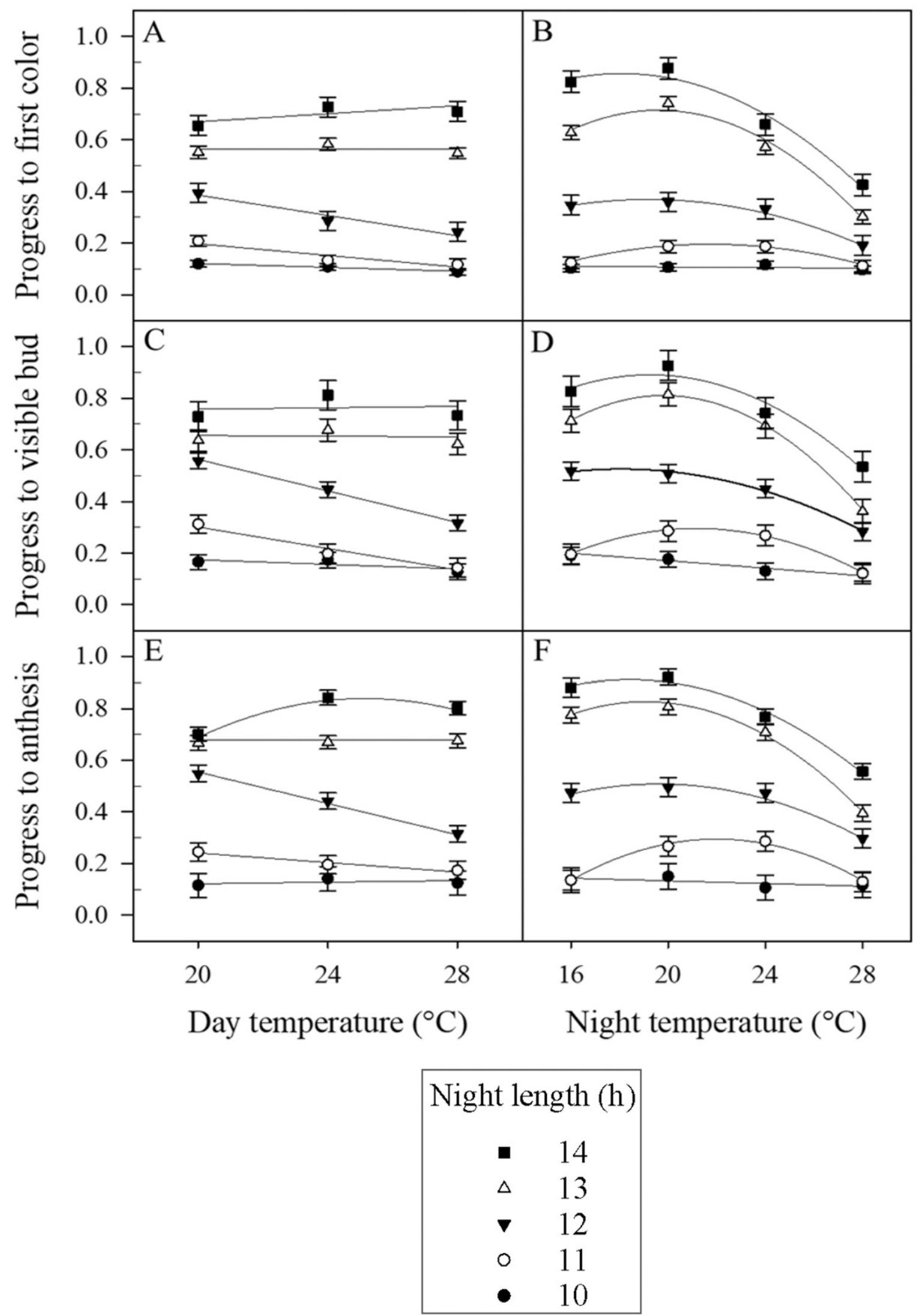

Fig. 3. Poinsettia 'Prestige Red' plants were placed under night lengths (NL) of 10,11, 12, 13, or $14 \mathrm{~h}$ for $17 \mathrm{~d}$ and then consolidated to a fully inductive environment (14-h NL, $24 / 20^{\circ} \mathrm{C}$ day/night temperature) until anthesis. The relative rate of progress to first color, visible bud, and anthesis are reported for each day temperature $(\mathbf{A}, \mathbf{C}, \mathbf{E})$ and night temperature $(\mathbf{B}, \mathbf{D}, \mathbf{F})$ treatment. Each data point in the day temperature figures represents the average time to reach a flowering response across the four night temperatures and vice versa for the night temperature figures. Error bars represent \pm 1 SE. 
These data clearly demonstrate that when DT are relatively cool $\left(20^{\circ} \mathrm{C}\right)$, the greatest increase in progress to anthesis occurs as NL increases from 11 to $12 \mathrm{~h}$, whereas at the warmest DT $\left(28^{\circ} \mathrm{C}\right)$ the greatest increase in progress to all three flowering responses occurs as NL increases from 12 to $13 \mathrm{~h}$.

For 'Prestige Red', no differences in progress to first color, visible bud, and anthesis were observed for the different NT treatments at the 10-h NL (Fig. 3B, D, and F), whereas at the $11-\mathrm{h} \mathrm{NL}$, progress to the three flowering responses increased if NT was 20 and $24^{\circ} \mathrm{C}$. At the $11-\mathrm{h} \mathrm{NL}$, no increase in progress to flower was observed compared with the $10-\mathrm{h} \mathrm{NL}$ if the NT was 16 or $28^{\circ} \mathrm{C}$. At the 12-h NL, progress to flower increased significantly at all temperatures compared with the 11-h NL; however, progress to flower decreased significantly as NT increased from 24 to $28^{\circ} \mathrm{C}$. Similarly, at the 13 - and $14-\mathrm{h}$ NLs, progress to flower continued to occur at a faster rate at all NT, but progress was much slower when NT increased from 20 to $28^{\circ} \mathrm{C}$ NT.

It is commonly observed that heat-delayed poinsettias are taller than those grown at moderate temperatures. In this experiment, the number of nodes formed during the experiment increased linearly as the days to visible bud increased. For example, days to visible bud for 'Orion Red' increased from 31 to $45 \mathrm{~d}$, whereas the number of nodes increased from 8 to 19 across all treatments, and days to visible bud for 'Prestige Red' increased from 35 to $51 \mathrm{~d}$, whereas the number of nodes increased from 8 to 19 . This suggests that taller plants resulting from heat delay conditions are a result of additional node formation before flower initiation in the shoot apex.

The results from this study demonstrate that poinsettia flowering response to temperature depends on NL. For both the heat-sensitive cultivar, Prestige Red, and the heat-tolerant cultivar, Orion Red, flowering occurred more rapidly at short NLs (10-12 h) when the DT was relatively cool $\left(20^{\circ} \mathrm{C}\right)$, whereas longer NLs (13-14 h) were required when DT was warm $\left(28^{\circ} \mathrm{C}\right)$. This suggests that when poinsettias are grown under natural NL conditions in early September through early October, cool DT will result in earlier flower initiation for both heat-tolerant and heat-sensitive cultivars.

Our temperature treatments were provided for only $17 \mathrm{~d}$ before plants were consolidated into a $24^{\circ} \mathrm{C}$ DT, $20^{\circ} \mathrm{C}$ DT, and 14-h NL environment. We expect that once the initial stages of flower initiation occur, warmer temperatures (e.g., $24^{\circ} \mathrm{C}$ and possibly $28^{\circ} \mathrm{C}$ ) increase the rate of flower development. For example, poinsettias grown continuously at $20^{\circ} \mathrm{C}$ will stimulate early flower initiation due to the interaction of temperature and photoperiod, but $20^{\circ} \mathrm{C}$ is not optimal for flower development, so the fastest flowering may not occur when $20^{\circ} \mathrm{C}$ is provided continuously (Grueber and Wilkins, 1994). Future studies focusing on flower initiation of poinsettia may consider providing treatments for just 10 to $14 \mathrm{~d}$ to minimize the potential to confound flower initiation and development responses.

The flowering responses of 'Prestige Red' were dramatically slower at high NT $\left(28^{\circ} \mathrm{C}\right)$, whereas 'Orion Red' showed relatively little change in flowering across NT. High NT caused slower flower development of 'Prestige Red' for all NL from 11 to $14 \mathrm{~h}$. This suggests that if high NT cannot be avoided due to prevailing temperatures, using blackout curtains to create longer NL will not entirely alleviate heat delay, but flowering will occur faster at a 14-h NL than if the plants were receiving natural NL $(\approx 12 \mathrm{~h})$ in the fall. For example, when the NT was $28^{\circ} \mathrm{C}$, the relative progress to anthesis of 'Prestige Red' occurred at a rate of 0.56 (days of progress to flower per day of treatment) at the 14-h NL compared with a rate of 0.29 at the $12-\mathrm{h} \mathrm{NL}$, which represents a $93 \%$ increase by changing from a natural $\mathrm{NL}(\approx 12$ h) to a black cloth situation $(\approx 14-\mathrm{h}$ NL). For this reason, black clothing poinsettias is an effective method for reducing the magnitude of heat delay in heat-sensitive cultivars. It should also be noted that the number of hours that the plants were exposed to the high NT temperatures increased as NL increased, thus the 14 -h NL $\times 28^{\circ} \mathrm{C}$ NT treatment experienced 2 additional hours of high temperature compared with the 12 -h $\mathrm{NL} \times 28^{\circ} \mathrm{C}$ NT treatment. Despite this, the $14-\mathrm{h}$ NL treatment flowered faster, thus underscoring the benefit of longer NL to compensate for heat delay.

Our results show that the data presented by Schnelle (2008) and Berghage et al. (1987) are not actually in conflict. Schnelle (2008) conducted experiments under 12-h NLs and reported that time to flower increased with ADT, and our data in the 12-h NL treatments are in agreement. DT and progress to anthesis were inversely proportional at the 12-h NL in both cultivars. Berghage et al. (1987) conducted their study under 14-h NLs and reported that time to flower increased with NT alone, and our data in the 14-h NL treatments are also in agreement. Increasing NT delivered to 'Prestige Red' from 20 to $28^{\circ} \mathrm{C}$ decreased progress to anthesis at the 14-h NL. 'Orion Red' showed a significant decrease in progress to anthesis under 13 -h NLs at the $28^{\circ} \mathrm{C}$ NT relative to the 20 and $24^{\circ} \mathrm{C}$ NT treatments; however, increasing the NL to $14 \mathrm{~h}$ reduced the adverse effect of the $28^{\circ} \mathrm{C}$ NT.

Poinsettia cultivars have traditionally been classified by their response time, which is defined as the number of weeks of continuous inductive NL required to reach anthesis. 'Orion Red' is considered an "early season" cultivar with a response time of 7.5 to 8 weeks, whereas 'Prestige Red' is considered a "late season" cultivar with a response time of 9 weeks. Our data demonstrate that increasing NLs decreased the overall time to flower in both cultivars, but a difference of 8 to $10 \mathrm{~d}$ to anthesis between cultivars was maintained across all NLs. The overall cultivar response time from initiation to anthesis does not necessarily correlate with enhanced tolerance to supra-optimal temperatures during flower initiation. For example, cultivars such as Prestige Early Red and Christmas Glory Red have similar response times to Orion Red, but both cultivars are considered to be heat-sensitive (personal communication).

Cultivar selection is one of the most critical steps for poinsettia growers to consider when attempting to avoid heat delay, and these decisions could be improved if breeders evaluate new cultivar introductions for susceptibility to heat delay. The current study provides guidelines for poinsettia breeders to evaluate the effect of high temperatures on flower initiation and early development in new cultivars. To achieve this, we recommend using two DT $\times$ NT regimens of 24/20 and $28 / 28^{\circ} \mathrm{C}$ under both 12 - and 14 -h NLs to assess the temperature sensitivity of a cultivar under NL that reflect both natural days and black cloth situations. For example, at the 12h NL, 'Orion Red' flowered $4 \mathrm{~d}$ faster when initiating under DT/NT of $24 / 20^{\circ} \mathrm{C}$ relative to $28 / 28^{\circ} \mathrm{C}$, which demonstrates that this cultivar is slightly susceptible to delay under NLs similar to natural photoperiod conditions in September. 'Orion Red' did not demonstrate a delay in flowering at these two temperature regimens when provided a 14-h NL. At the 12-h NL, 'Prestige Red' flowered $\approx 10.5 \mathrm{~d}$ faster when initiating under DT/NT of $24 / 20^{\circ} \mathrm{C}$ relative to $28 / 28^{\circ} \mathrm{C}$. 'Prestige Red' grown at a 14-h NL flowered $8.5 \mathrm{~d}$ faster at DT/NT of $24 / 20^{\circ} \mathrm{C}$ relative to 28 / $28^{\circ} \mathrm{C}$. Furthermore, despite the observed delay at a 14-h NL on 'Prestige Red' grown under a DT/NT of $28 / 28^{\circ} \mathrm{C}$, this treatment actually flowered faster than the $24 / 20^{\circ} \mathrm{C}$ treatment at $12 \mathrm{~h}$. Thus, growers located in regions where high temperatures are expected during September could produce heat-sensitive varieties if a black cloth system is available to provide 14-h NLs.

Poinsettia is often described as an obligate short-day plant and several studies have identified a critical NL for poinsettia to be between 11.5 and $12.5 \mathrm{~h}$ depending on cultivar (Ecke et al., 2004; Grueber, 1985; Kristofferson, 1969; Larson and Langhans, 1962; Langhans and Miller, 1959). However, our data show that a low rate of relative progress toward flowering occurs at 10- to 11-h NLs under certain temperatures. For example, 'Orion Red' demonstrated significant differences in relative progress to anthesis under a DT of $20^{\circ} \mathrm{C}$ under 10 -h NLs; both cultivars showed significantly higher rates of relative progress to anthesis at NT of 20 and $24^{\circ} \mathrm{C}$ relative to 16 and $28^{\circ} \mathrm{C}$ at 11 -h NLs. Furthermore, Evans et al. (1992) demonstrated that poinsettia will initiate a cyathium under long days (natural-day photoperiods at lat. $44^{\circ} 57^{\prime} \mathrm{N}$ with daylight extension lighting from 1700 to $2200 \mathrm{HR}$ ) once a cultivar-specific long-day leaf number has been achieved; however, this cyathium fails to develop to anthesis. Thomas and Vince-Prue (1997) described the facultative floral response as when flowering eventually occurs regardless of photoperiod; thus, technically speaking, poinsettia should be 
characterized as a facultative short-day plant with regard to flower initiation. However, flower development does not occur under long-day conditions, which indicates that poinsettia is an obligate short-day plant with regard to flower development. A similar phenomenon has been reported in the short-day plant chrysanthemum (Dendranthemum $\times$ grandiflorum) in which flower buds initiate under long days but fail to develop unless short days are provided (Cockshull, 1976).

\section{Literature Cited}

Berghage, R., R. Heins, W. Carlson, and J. Biernbaum. 1987. Prevent flower delay. Greenhouse Grower 5:78-79.

Camberato, D.M., R.G. Lopez, and B.A. Krug. 2012. Development of Euphorbia pulcherrima under reduced finish temperatures. Amer. Soc. Hort. Sci. 47:745-750, doi: 10.21273/HORTSCI.47.6.745.

Cathey, H.M. 1997. Announcing the AHS plant heat-zone map. Amer. Gard. 76(5):30-37.

Cockshull, K.E. 1976. Flower and leaf initiation by Chrysanthemum morifolium Ramat in long days. J. Hort. Sci. 51:441-450, doi: 10.1080/ 00221589.1976 .11514712 .

Ecke, P., III, J. Faust, A. Higgins, and J. Williams. 2004. The Ecke Poinsettia Manual. Ball Publishing, Batavia, IL.

Evans, M.R., H.F. Wilkins, and W.P. Hackett. 1992. Meristem ontogenetic age as the controlling factor in long-day floral initiation in poinsettia. J. Amer. Soc. Hort. Sci. 117:961-965, doi: 10.21273/jashs.117.6.961.

Grueber, K.L. 1985. Control of lateral branching and reproductive development in Euphorbia pulcherrima Willd. Ex Klotzch. Univ. of Minn., St. Paul, Ph.D. Diss. Abstr. 8603843.

Grueber, K.L. and H.F. Wilkins. 1994. Inflorescence initiation and development of poinsettia under various thermo and photo environments, p. 23-29. In: E. Strømme (ed.). Scientific basis of poinsettia production. Agr. Univ. Norway, Aas, Norway.

Kofranek, A.M. and W.P. Hackett. 1965. The influence of daylength and night temperature on the flowering of poinsettia, cultivar 'Paul Mikkelsen'. Proc. Amer. Soc. Hort. Sci. 87:515-520.

Kristoffersen, T. 1969. Influence of daylength and temperature on growth and development in poinsettia (Euphorbia pulcherrima Willd.) Symp. Flower Regulat. Flor. Crops. 14:79-90, doi: 10.17660/actahortic.1969.14.7.

Langhans, R.W. and R.A. Larson. 1959. The influence of day and night temperatures on the flowering of poinsettia (Euphorbia pulcherrima). Proc. Amer. Soc. Hort. Sci. 75:748-752.

Langhans, R.W. and R.O. Miller. 1959. Influence of daylength, temperature and number of short days on the flowering of poinsettia (Euphorbia pulcherrima). Proc. Amer. Soc. Hort. Sci. 75:753-760.

Larson, R.A. and R.W. Langhans. 1962. The influences of temperature on flower bud initiation in poinsettia (Euphorbia pulcherrima). Proc. Amer. Soc. Hort. Sci. 82:552-556.
Roberts, R.H. and B.E. Struckmeyer. 1938. The effects of temperature and other environmental factors upon the photoperiodic responses of some of the higher plants. J. Agr. Res. 56:633-677.

Schnelle, R. 2008. Timing, duration, and diurnal distribution of supraoptimal temperatures affect floral initiation of poinsettia. Univ. of Fla., Gainesville, PhD Diss. Abstr. 3425540.

Schnelle, R., J.E. Barrett, and D.G. Clark. 2006. High temperature delay of floral initiation in modern poinsettia cultivars. Acta Hort. 711:273-278, doi: 10.17660/ActaHortic.2006.711.36.

Thomas, B. and D. Vince-Prue. 1997. Photoperiodism in plants. 2nd ed. Academic Press, San Diego, CA, doi: 10.1016/b978-012688490-6/50002-4.

Trejo, L., T.P. Feria Arroyo, K.M. Olsen, L.E. Eguiarte, B. Arroyo, J.A. Gruhn, and M.E. Olson. 2012. Poinsettia's wild ancestor in the Mexican dry tropics: Historical, genetic, and environmental evidence. Amer. J. Bot. 99(7):1146-1157, doi: 10.3732/ajb.1200072.

U.S. Department of Agriculture. 2019. Floriculture crops 2018 summary. U.S. Dept. Agr., Washington, D.C.

U.S. Naval Observatory. 2007. Astronomical Applications Department. 22 June 2021. <http://aa. usno.navy.mil/>

Vose, R.S., D.R. Easterling, K.E. Kunkel, A.N LeGrande, and M.F. Wehner. 2017. Temperature changes in the United States. Climate Science Special Report: Fourth National Climate Assessment, Volume I. U.S. Global Change Research Program, Washington, DC, p. 185-206, doi: $10.7930 / J 0 N 29 V 45$. 